\title{
Qualitative assessment of the Upper limb of child with cerebral palsy
}

\author{
Zineb Talem', Fatima Benali², Houria Achouri ${ }^{3}$, Fatima Bouchiba ${ }^{4}$, Ilhem Bentedjini ${ }^{5}$, \\ Khaled Layadi ${ }^{6}$ \\ Faculty of Medicine of Oran, Université Oran 1, Algeria \\ ${ }^{2}$ Corresponding author

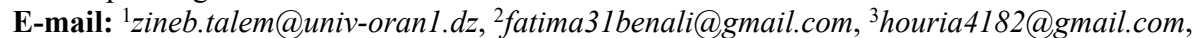 \\ 4fatima.bouchiba@yahoo.com, ${ }^{5}$ tadjdineilhem@gmail.com, ${ }^{6}$ layadi.k@yahoo.com
}

Received 3 October 2019; received in revised form 3 November 2019; accepted 10 November 2019 DOI https://doi.org/10.21595/chs.2019.21074

A) Check for updates

Copyright (C) 2019 Zineb Talem, et al. This is an open access article distributed under the Creative Commons Attribution License, which permits unrestricted use, distribution, and reproduction in any medium, provided the original work is properly cited.

\begin{abstract}
The management of the upper limb (MS) of the child with cerebral palsy (CP) is long past that of walking; many factors make it difficult to study the MS of the child PC: The variability of involvement (spasticity, dystonia) with, unlike the lower limb, the significant impact of associated disorders (sensory, cognitive) for functional use of the upper limb. The great diversity of tasks performed by the upper limb in contrast to the lower limb (cyclic activity of walking) which requires many assessment tools with standardized and age-appropriate tasks, for the multiple treatment goals. But for over fifteen years, with the advancement of research on brain plasticity, the development of new tools and access to certain therapeutics this care has taken a more important place and especially much earlier in the arsenal therapeutic. So we must emphasize the importance of choosing valuable tools for evaluation. .car if the used tests are not relevant, the relevance of the therapeutic action that will follow becomes her also questionable, Moreover, this means also that the therapist has some knowledge of possible therapeutics in order to able to inform his patient and refer him to appropriate stakeholders.
\end{abstract}

Keywords: cerebral palsy, upper limb, assessment, capacity, performance rehabilitation.

\section{Introduction}

According to Arner (2008) [1], the cerebral palsy (CP) is the most common cause of physical disability in childhood and the upper limb therapy in childhood is neglected for a long time after the lower limb one.

But, since about fifteen years, with the advancement of research on brain plasticity and the development of new tools and access to certain therapies, the functional importance of the upper limb has becoming more and more obvious and has gradually taken a very important place, especially much earlier in the therapeutic arsenal $[2,3]$.

According to Daigneault (2003) [4] "The realization of a global and fine motor act is the product of the good development and the integration of several components".

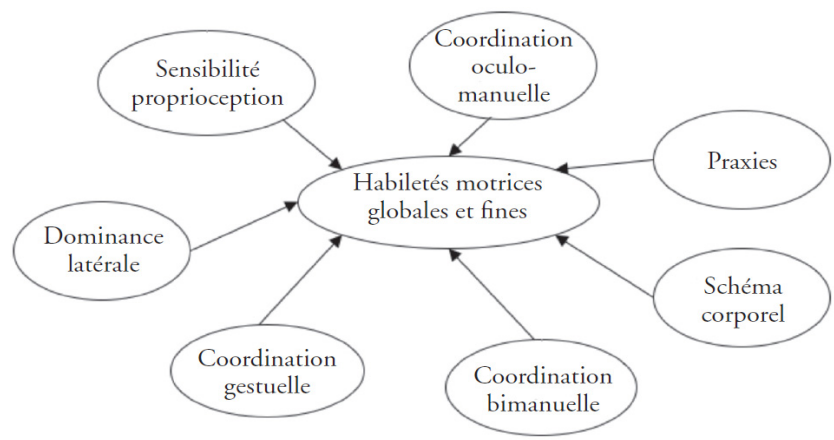

Fig. 1. Components associated with motor skills masteryles [4] 
Rudman et Hannah, through their work in 1998 [5], provide a framework that clarifies the different criteria a tool must meet to the requirements of a relevant evaluation.

Before we start our main topic, the evaluation methods of the upper limb of children with $\mathrm{CP}$, It's better to get some small definitions of these terms: the sensorimotor coupling, the neuroplasticity and cerebral palsy, the posture and the manual traction.

\section{The sensorimotor coupling}

The proprioception and the tact (the haptic perception) involve in the development of our body diagram [6]. So if we trample the brain by increasing the number of sensory afferences arrived at it, we recreate and increase the cortical upper limb projection. The pathway of these neurone's axons terminates at the primary somatosensory cortex of the parietal lobe where the Visual Somatosensory Integration and Balance happens. It is also in this area that it would coordinate [7]. This primary somatosensory area has a close relation with the primary motor area which generates the execution of voluntary movements. The connection between these two areas occurs via the fissure of ROLANDO.

When we release a voluntary movement, the primary motor cortex is activated, even the premotor primary one and the supplementary motor cortex performing a sensorimotor loop. So, the sensory information treatment will be a priority in any motor voluntary action executed [8].

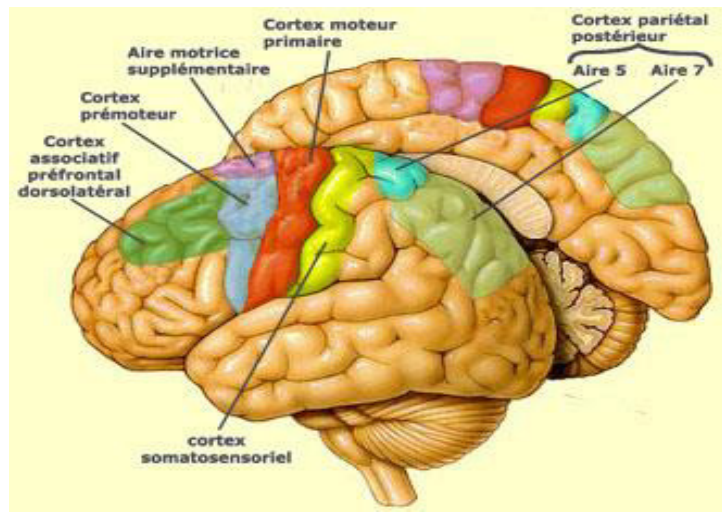

Fig. 2. The supplementary motor area

The supplementary motor area (SMA) and the premotor cortex are included in the programmation and the execution of movements, the primary motor cortex contributes in the movement coding. A copy from this motor plan will be sent to parietal and cerebellum areas: it is the efferent copy. The parietal association cortex (especially BA5 and BA7), represents the body movement images on the cortex and it is activated "in the case of real and imagined movements".

As a Conclusion: The sensorimotor loop link between the sensations and the movement, between the initiation, son execution and the adaptation of voluntary movement.

\section{The neuroplasticity}

Central nervous system (CNS) plasticity results in functional changes and structural effects of the brain, which have the effect of deteriorating or improving functions; these changes in the neural circuit can dynamically respond to the environment and the experience [9].

During childhood and for someone suffering from PC, there are certain 'critical periods' for development during which the brain plasticity increases.

According to Eliasson 2014 [10], the corticospinal projections from the hand make a change in the brain organization before reaching one year of age. However, if a particular brain zone becomes damaged, a process of recovery from brain injury occurs thanks to two mechanisms: 
- The restitution: spontaneous physiologic recovery occurs after brain damage, it heals itself.

- The substitution or compensation: refers to recovery via transfer/reorganization of functions from damaged brain tissue to healthy sites.

In the last case, the transfer can be done in three modes [11, 12]:

1. Interhemispheric transfer: functions transfer to the analogous site in the non-damaged hemisphere.

2. Intrahemispheric transfer: reorganization of functions within the damaged hemisphere.

3. Intrahemispheric maintenance: skills subsumed by damaged tissue are maintained within that tissue, resulting in maximum dysfunction.

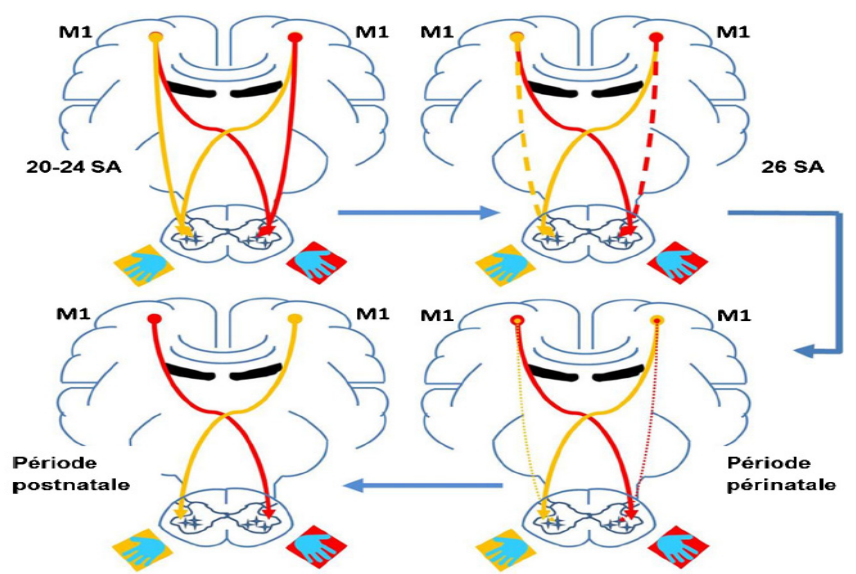

Fig. 3. Schematic representation of the development and degeneration of ipsiand contralateral pyramidal bundles during fetal life and early years of life.

Dates are indicated approximately. SA: week of amenorrhea [12]

One-sided CP often causes a lack or interruption of the development of the cortical representation of the affected upper limb, which influences the functional capacity of it [12].

According to Staudt and Khunke (2008) [13], in patients with acquired versus congenital damage; the corticospinal reorganization of primary motor control of the upper limb is done in two ways if the cortex presentation of the upper limb is partially affected: the upper limb concerned will be controlled by the injured hemisphere (contralateral corticospinal projections)

If it is completely damaged: the upper limb concerned will be controlled by the non-damaged hemisphere (ipsilateral corticospinal projections). These ipsilateral projections exist in postnatal period and disappear before the first year of life, because of the activity-dependent competition between developing corticospinal terminations.

For Guzetta (2007) [14], the type of reorganization and the choice of the used method can be influenced by the size and site of damage.

The posture and the manual motricity:

Postural stability is essential for the optimal use of MS by diminishing control and attention to the rest of the body. Different functions of the posture: Support or antigravity function, the hold function, the recovery function and the equilibration function

It must orientate the body towards the object, and make visible the object and the hand without forcing the subject to move. It is also involved in joint stabilization.

The stages of manual motor skills [15]:

a) Approach: consists of two phases: the transport phase (ballistics) and the adjustment phase of the hand.

b) Taken: with two types of catch: the power take-offs and the precision.

c) Manipulation: it is an exploration of the object, which activates all sense of the subject.

d) Restitution: This is the time when the object is dropped. There is a decrease in the force 
exerted and an opening of the hand, there are two types of restitutions: to let go and the deposit. This phase requires an efficient segmental control because the arm is not stabilized; it is difficult to be précised.

Therefore, the manual function is complex, and influenced by many parameters (environmental or personal); its evaluation is a fundamental step in the care. The choice of balance is made according to the objective (problematic of daily life, indication of surgery, of rehabilitative care ...) [16]. It must be based on a good knowledge of the benefits and disadvantages of each test there is no universal, magical tool that responds to all assessment situations.

\section{The qualitative clinical evaluation}

It is a functional evaluation measuring effectiveness in activities of daily life. It leads to the child's establishment of age curves using codified and calibrated tests for determined ages.

1) Evaluation of the possibilities of lengthening muscles (STRETCH REFLEX):

By the angle $A_{o}$ search where the minimum elastic force encountered by the examiner is perceptible manually (passive mobilization); Then we note the angle Ax obtained during the maximum elongation of the muscle [17].

It is interesting to note that since 1955, G. Tardieu [18] had proposed before the World Commission of the $\mathrm{PC}$ not to talk about spasticity in the presence of myotatopathological reflexes in distinguishing the two components phasic (kinetic) or $A_{o}=A_{x}$ and tonic (static) or $A_{X}$.

2) Basal contractions (factor B):

Its co-contractions or movement's slow athetosics existing in the state of "rest" (decubitus) called to exaggerate in the movement. It represents a background of interference existing before the arrival of any other program of action [17].

We all know that PC subjects have contracted muscles (Basal contractions producing irrepressible movements Fact B and slow athetoid movements aggravated by anxiety, Emotivity and Fact E).

We must resort to automatic relaxation maneuvers which we did not have the practice of lower limb level than upper limbs to get the necessary relaxation during the evaluation maneuver.

These maneuvers temporarily inhibit pathological contractions and put the child in a situation close to normal, thus facilitating access to activities.

"The maneuvers must be practiced in a gentle and very progressive manner. The operator must in all circumstances avoid reaching the threshold of nociceptivity. They use the dexterity of the examiner and require some training time to use without hesitation and without discomfort for the subject" (Le Métayer, 2005) [18].

3) Anxiety and emotion:

The examiner may note the differences in the degree of contraction according to the state of anxiety of the subject [19], it is to be distinguished from emotional reactions that are less prolonged but can trigger very large increases in co-contractions and movements abnormal when being present.

4) Factor E:

These are contractions caused by external stresses (sudden sound, skin contact, fast movements in front of the eyes).

5) Antigravity contractions:

This is the exaggeration of muscle contractions of the upper limb when placing the patient in a sitting position by performing 6 tests and showing him how to do it.

They make it possible to evaluate the power of control and maintenance antigravity of the subject on the contractions causing the postures abnormalities (basal factor), as well as the selectivity power in the voluntary order. The quotation is made using G. Tardieu's scale [18], from 1 to 5 .

6) The evaluation of muscle strength:

The evaluation of muscle strength by function is preferred over testing because the child PC 
often lacks selectivity in his movements.

In very young children, it is then replaced by visual observation of their spontaneous and / or guided activity. Unless a toxin injection treatment decision is made, Functional evaluation is completed by a muscle evaluation by muscle.

7) Vision evaluation

It is necessary to note the seizure of the object by the look, its location and maintenance of fixation on the object before and during the approach of the hand until the grip.

8) The evaluation of perceptions:

A. tests of tactile gnosis:

a) Test of everyday objects:

Using the tactile recognition of the "five objects" conventional [20]: a cube of $2 \mathrm{~cm}$ of edge, a pencil, a ball, a box of matches or a wooden box of the same size and a coil.

- Recognize what is smooth, a little rougher, very rough.

- Distinguish by contact the metal of the wood or a fur of a brush.

- Distinguish what is cold from what is lukewarm.

Fault of test: it is necessary to compare the level of recognition of such subject with the age range of two to three years.

b) Test geometric shapes:

The conditions of the event $[17,20]$ :

- The game of forms is shown to the child in its entirety.

- From a form is put in the hand of the subject without being able to see it and it is turned in the hand by the examiner.

- Then, the shape is replaced with the others out of the view of the subject.

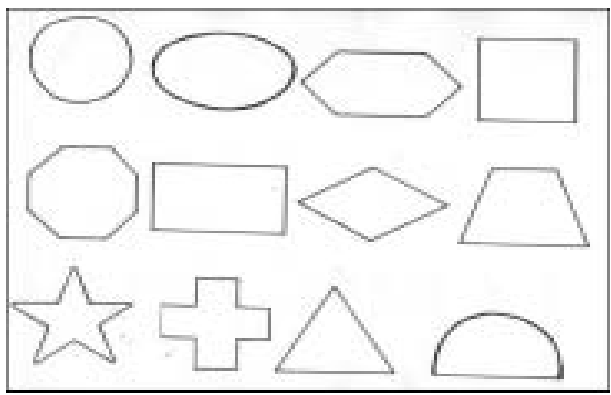

Fig. 4. Geometric shapes used to evaluate tactile gnosies

B. The evaluation of proprioceptive gnosis and practognosiques:

The subject is sitting on a chair without pressing the back on the backrest [18].

It is asked to point the center of a target three consecutive times $1 \mathrm{~cm}$ in diameter without looking away.

The target is located in the parasagittal plane passing through its shoulder, at a distance requiring limited extension of the elbow at $10^{\circ} / 15^{\circ}$, and below the level of the center of the joint, It is then asked to point the eyes at the target three more times open.

For the fourth time without sight; the gap between the center of the target and the point of contact of the finger is measured.

9) Graphic evaluation:

This test can only be used with children who have reached level of graphics and sufficient understanding to follow the instructions.

Hypermetria [17]: Invited to draw a line between the two lines, a subject valid commits errors to start due to poor estimates of the distance between two lines. Three attempts are enough for the aiming to be precise. The hypermypertric greatly exceeds second line despite the errors of which he is aware. He finally chooses to slow down very visibly his gesture and step by step he directs 
his hand towards the second line.

Adiadochokinesia: In this event, the subject is invited to join alternately the two traits without interrupting the gesture. The valid subject executes the trait by adopting a cadence that allows him to change the meaning of his features without a solution of continuity. The adiadocokinetic subject makes long stops before changing the direction of his features in an opposite.

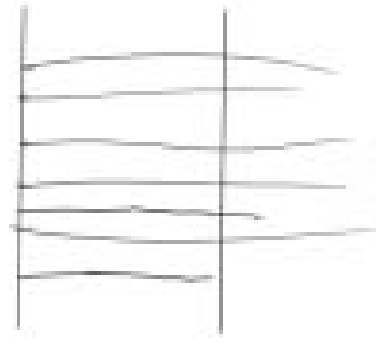

Fig. 5. Hypermetria

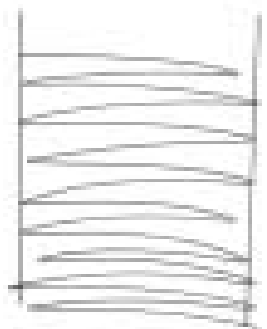

Fig. 6. Adiadochokinesia

Dyschronometry: The child was invited to trace the course of the house to the car by adopting a constant speed and then come back home keeping the same speed [15]. The trait reflects a disorder of dyschronometry to which periodical oscillations are superimposed.

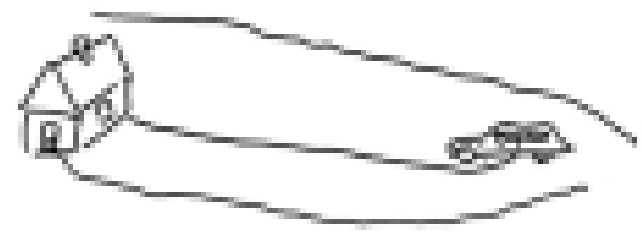

Fig. 7. Dyschronometry [17]

The child was asked to trace the path from home to car by adopting a constant speed, then come back home keeping the same speed.

The line expresses a disorder of dyschronometry with superimposed oscillations

\section{Conclusions}

The defi in engine quality and aptitudes of upper appendage was watched through tall scores in MACS and GMFCS and moo scores on Journey in children with CP from Rio Grande do Norte, permitting to induce useful impediments with respect to objects control and resulting reliance amid life exercises. Other than, such rebellious were exceedingly related, supporting their concomitant use. Therefore, arranging suitable treatment in arrange to make strides upper appendage work (arm, wrist, hand, and fingers) and freedom in life is essential, and it ought to be based on a comprehensive and point by point evaluation of the upper limb.

Thus, we recommend assist ponders to be created in this region, interpretation and approval of Journey manual into Portuguese in arrange to form it more available for wellbeing experts, basically physical specialists and/or word related advisors in northeastern locale of Brazil, where there are no ponders portraying upper appendage disability profile by trusted and dependable clinical instruments. Therefore, more research in this area with larger samples in order to trace the existing profile is necessary.

The upper limb has a vital role in the life: it is the pillar of independence, it also a sensory, social, expression and communication function

The evaluation tools are numerous but it is important to define specific objectives to make the best use of them as well as a standardization and homogenization of the practices seem necessary between professionals. 
As professionals, we need to help the child improve the integration of the upper limb into everyday concerns and make the best use of his/her abilities so that he/she can put in place a transfer of his/her acquired skills.

\section{References}

[1] Basu A. P., Pearse J., Kelly S., Wisher V., Kisler J. Early intervention to improve hand function in hemiplegic cerebral palsy. Frontiers in Neurology, Vol. 5, 2015, p. 281.

[2] Chabrier S., Roubertie A., Allard D., Bonhomme C., Gautheron V. New developments in spastic unilateral cerebral palsy. Revue Neurologique, Vol. 166, Issue 6, 2010, p. 565-573.

[3] Bard P. R. To orient choices by a functional assessment of the upper limb based on relevant tools. Motricité Cérébrale, Vol. 33, Issue 2, 2012, p. 54-61.

[4] Daigneault G., Leblanc J. Rééducation de la motricité des membres supérieurs de l'enfant: les spécificités de l'ergothérapeute. La motricité fine, dans Des idées plein la tête. Montréal, de la Chenelière, 2003.

[5] Rudman D., Hannah S. An instrument evaluation framework: description and application to assessments of hand function. Journal of Hand Therapy, Vol. 11, 1998, p. 266-77.

[6] Hanneton S., Jacobs S., Roby Brami A. Aspects neurophysiologiques et neuropsychologiques de l'utilisation d'outils. Publication Électronique Arobase, Vol. 1, 2015, p. 114-126.

[7] Junker Tschopp C. Corps Amputé, Corps Appareillé: Comment Reconstruire Et Réinvestir Ce Corps Malmené Dans Son Unité? Perspectives Neuro-Psychomotrices. Entretiens de Bichat Psychomotricité, Paris, 2012.

[8] Colteu C. Le Phénomène D'exclusion Du Membre Supérieur Chez L'adulte: Description Et Approches Thérapeutiques Conventionnelle Et Par Miroir. Thèse de doctorat en médecine, Université Henri Poincaré, Nancy, 2010.

[9] Inguaggiato E., Sgandurra G., Perazza S., Guzetta A., Cioni G. Brain reorganization following intervention in children with congenital hemiplegia: a systematic review. Neural Plasticity, Vol. 2013, 2013, p. 356275.

[10] Eliasson A. C., Sjöstrand L., Ek L., Krumlinde Sundholm L., Tedroff K. Efficacy of baby-CIMT: study protocol for a randomised controlled trial on infants below age 12 months, with clinical signs of unilateral CP. BMC Pediatrics, Vol. 14, 2014, p. 141.

[11] Anderson V., Spencer Smith M., Wood A. Do children really recover better? Neurobehavioural plasticity after early brain insult. Brain, Vol. 134, Issue 8, 2011, p. 2197-2221.

[12] Dinomais M., Hertz Pannier L., Nguyen S. The Tich Reorganization of the sensorimotor cortex in children with spastic unilateral cerebral palsy: What can we learn from neuroscience? Motricité Cérébrale, Vol. 35, 2014, p. 3-14.

[13] Kuhnke N., Juenger H., Walther M., Berweck S., Mall V., Staudt M. Do patients with congenital hemiparesis and ipsilateral corticospinal projections respond differently to constraint-induced movement therapy? Developmental Medicine and Child Neurology, Vol. 50, Issue 12, 2008, p. 898-903.

[14] Guzetta A., Cioni G., et al. Brain reorganization following intervention in children with congenital hemiplegia: a systematic review. Neural Plasticity, 2013.

[15] Effgen S. K. Meeting the Physical Therapy Needs of Children. F.A. Davis, Philadelphia, 2013.

[16] Bard Pondarré R., Castan C. Interests and limits of the use of quantitative tests to assess upper limb function in patients with cerebral palsy. Motricité cérébrale, Vol. 38, 2017, p. 59-70.

[17] Thétio M., et al. Upper limb of the child affected with cerebral palsy. Use of the botulinum toxin: Evaluation, therapies, strategies. Motricité Cérébrale, Vol. 33, 2012, p. 101-110.

[18] Le Métayer M. Evaluation clinique factorielle - Techniques d'examen. Motricité Cérébrale, Vol. 26, Issue 4, 2005, p. 167-176.

[19] Thiery N. Motricité Active Et Utilisation Du Membre Plégique. Mémoire En Vue De L'obtention Du Diplôme D'état De Psychomotricité. Université Paul Sabatier, Toulouse, 2013, p. 93.

[20] Gagnard L. Évaluation des gnosies manuelles. Motricité Cérébrale, Vol. 7, 1986, p. 113-118. 